\section{(A) OPEN ACCESS}

\title{
Vulnerabilities, health needs and predictors of high-risk sexual behaviour among female adolescent sex workers in Kunming, China
}

\author{
Xu-Dong Zhang, ${ }^{1}$ Marleen Temmerman, ${ }^{1}$ Yan Li, ${ }^{2}$ Wei Luo, ${ }^{3}$ Stanley Luchters ${ }^{1,4,5}$
}

\begin{abstract}
${ }^{1}$ International Centre for Reproductive Health, Department of Obstetrics and Gynaecology, Ghent University, Ghent, Belgium

${ }^{2}$ School of Public Health, Kunming Medical University, Kunming, Yunnan, China ${ }^{3}$ STI Unit, Kunming Center for Disease Control, Kunming, Yunnan, China

${ }^{4}$ Centre for International Health, Burnet Institute, Melbourne, Victoria. Australia ${ }^{5}$ Department of Epidemiology and Preventive Medicine, School of Public Health and Preventive Medicine, Monash University, Australia
\end{abstract}

\section{Correspondence to} Xu-Dong Zhang, International Centre for Reproductive Health Ghent University,

De Pintelaan 185, P3 B-9000,

Ghent 650500, Belgium; stella_zxd@hotmail.com

Received 4 June 2012 Revised 10 October 2012 Accepted 3 November 2012 Published Online First 8 December 2012

\begin{abstract}
Objectives This study assessed social and behavioural predictors for sexual risk taking and sexually transmitted infections (STIs) including HIV among adolescent female sex workers (FSWs) from Kunming, China. Additionally, health services needs and use were assessed.

Methods A cross-sectional survey was conducted in 2010. Using snowball and convenience sampling, selfidentified FSWs were recruited from four urban areas in Kunming. Women consenting to participate were administered a semi-structured questionnaire by trained interviewers identified from local peer-support organisations. Following interview, a gynaecological examination and biological sampling to identify potential STIs were undertaken. Descriptive and multivariable logistic regression analyses were performed.

Results Adolescent FSWs had a mean age of 18.2 years and reported numerous non-paying sexual partners with very low rate of consistent condom use (22.2\%). Half (50.3\%) the respondents had sex while feeling drunk at least once in the past week, of whom $56.4 \%$ did not use condom protection. STI prevalence was high overall (30.4\%) among this group. Younger age, early sexual debut, being isolated from schools and family, short duration in sex work, and use of illicit drugs were found to be strong predictors for unprotected sex and presence of an STI. Conversely, having access to condom promotion, free HIV counselling and testing, and peer education were associated with less unprotected sex. The majority reported a need for health knowledge, free condoms and low-cost STI diagnosis and treatment.

Conclusions There is an urgent need to improve coverage, accessibility and efficiency of existing interventions targeting adolescent FSWs.
\end{abstract}

\section{BACKGROUND}

Young people aged 15-24 years, predominantly young women, account for $41 \%$ of all new HIV infections globally. ${ }^{1}$ A nationwide study in China assessing sexual and reproductive health services among youth indicated that women aged 1519 years with low education and those who are mobile are most at risk of sexual and reproductive health problems, including unplanned pregnancies and sexually transmitted infections (STIs) such as $\mathrm{HIV}^{2}$ In particular, girls involved in sex work and those who use illegal substances and alcohol are at increased risk and are the new face of the HIV/STI pandemic. $^{3} 4$ Importantly, adolescent female sex workers (FSWs) have often been neglected by HIV/ STI strategies and service providers, partly due to the traditional assumption that adolescents should attend school with family support and abstain from sexual intercourse despite being legally old enough (the legal age for sex in China is 14 years).

Yunnan Province is a multiethnic area ${ }^{5}$ located in the 'Golden Triangle', a major international business and drug trafficking route, with relatively high HIV prevalence. ${ }^{6}$ By 2010, Yunnan accounted for $26 \%$ of China's reported cases, though it only makes up 3\% of China's population. Kunming, the capital city of Yunnan province, has over 6 million inhabitants including 3.1 million women. ${ }^{5}$ Rapid economic growth resulted in large-scale rural-to-urban migration with widening income gaps, which is an important driver of entry into sex work. In addition, more tolerant sexual attitudes and increased tourism boost the development of the commercial sex industry. ${ }^{8}$ A 2008 size estimation exercise in Kunming estimated there were 10196 (95\% CI 9488 to 10 903) FSWs (approximately $0.33 \%$ of Kunming's female population). ${ }^{9}$ However, this might be an underestimate due to a police crackdown likely impacting on the census method. ${ }^{10} 11$ Despite sex work being criminalised by law in China, many entertainment establishments (eg, karaoke clubs, night clubs, dancing halls, discos, bars) or personal service sectors (eg, hair washing rooms, hair salons, massage parlours, saunas, restaurants, hotels) are to some extent involved in facilitating sex services. ${ }^{12}$ Mainstream entertainment venues often also provide easy access to illicit drugs, including amphetamine-type stimulants, heroin and cannabis. ${ }^{13} 14$ Existing studies reveal a great heterogeneity among FSWs in China in terms of their working environment; yet, interventions do not sufficiently consider the diversity of contextual and social factors that influence the sexual behaviours of FSWs. ${ }^{12} 1516$ Limited data exist on young FSWs aged 15-19 years regarding their socio-demographic characteristics, working context, sexual and drug-using risk behaviour, HIV/ STI prevalence and health-seeking behaviour. This study aims to increase knowledge and understanding of the specific working contexts and vulnerabilities of adolescent FSWs in China, and understanding the predictors for unsafe sexual behaviour which will contribute to inform future targeted interventions.

\section{METHODS}

A cross-sectional survey of adolescent FSWs was conducted in collaboration with local academic 
institutes, the health department, community-based peer groups and Kunming Center for Disease Control (CDC). In addition, there are more than six peer groups/nongovernmental orgainsations supporting FSWs since 2002. Twenty-two outreach workers or peer educators from these support groups were trained as interviewers for this study.

The study recruited women aged 15-19 years who are selfreported FSWs who sell sex for money or goods at sex work venues. The study targeted FSWs who use any sort of drugs such as alcohol and tobacco, and also those who have used heroin, cocaine, opium, marijuana, morphine, yaba/amphetamines, pethidine, ketamine and ecstasy for non-therapeutic purposes at least once weekly in the last month. Sampling was done in two stages, with initial geographical mapping of work venues (116 locations identified) and size estimation predicting 493 adolescent FSWs as a sampling frame. A subsequent stratified random sampling encountered difficulties in enrolling study participants because of a nationwide police crackdown on the sex industry. As random sampling was shown not to be feasible, snowball and convenience sampling was applied aiming to recruit about half the target population. Some extension methods were adopted to minimise bias inherent in chainreferral sampling, including introduction of a dual-incentive mechanism that provided participants and their peer recruiters with a bonus to increase enrolment ${ }^{17}$; verification by Kunming CDC of participants' eligibility during pre-test and post-test HIV counselling; and definition of the recruitment area for each peer group with a fixed recruitment number to avoid undersampling or oversampling, and repeated recruitment in each area.

A face-to-face semi-structured questionnaire developed in Chinese was adapted from FSW and drug user behavioural surveillance developed by the Chinese National $\mathrm{CDC}^{18}$ and previous research from Kenya. ${ }^{19} 20$ The questionnaire, which took about 50 min to complete, was tested among 24 women to determine whether the content and language were appropriate for the study population. Information was collected on sociodemographic characteristics, entry into sex work, sexual behaviours, prevention knowledge and practices, substance use, reported STI symptoms, family planning and reproductive history, and health service use. Thereafter, a free clinical gynaecological examination, STI screening and voluntary HIV counselling and testing (HCT) were followed by referral of participants to Kunming CDC. A unique code was assigned to each participant to match their questionnaire with clinical and laboratory results and to avoid using names in any of the datasets.

\section{Ethical considerations}

The study protocol was approved by Yunnan institutional review board and the ethical committee of the Kunming Public Health Bureau. Women provided voluntary written informed consent separately for participation in the behavioural survey and HIV/STI testing. Willing participants were offered free HCT and STI testing services at Kunming CDC which were carried out following the national regulations regarding HIV prevention and management. ${ }^{21} 22$ Confidentiality was maintained during the recruitment process, questionnaire administration, data storage, and linking of laboratory and clinical data from test results. Prior to STI testing, healthcare staff asked participants for the best way to give test results to a parent or responsible person, and obtained their written consent. A reimbursement fee of RMB 50 (about US\$8) was given to the participants to compensate for their time and transport investment. Furthermore, participants could receive free health services through collaborating organisations, including outreach and peer education, standardised STI treatment, CD4 testing and antiretroviral treatment if indicated.

\section{Study measures}

Chinese public health and social science research suggests that there are distinct typologies for FSWs according to workplace and sexual risk, ${ }^{10} 16$ 23-28 with FSWs at 'low-end' establishments (eg, karaoke clubs, barbershops, dancing halls) having increased risks of HIV and STIs. Moreover, since 2005, China's HIV prevention strategy has aimed to strengthen intervention programmes to better address FSWs' internal diversity, and to promote behavioural change effectively. ${ }^{29}$ In this study, which is based on previous research of sex work in Yunnan and China as a whole, ${ }^{1023-26}$ we classified participants as 'higher risk' or 'lower risk' depending on their primary work setting. Participants at higher risk were those who walked the streets, worked in bars, small roadside guesthouses/hotels with managers or pimps, foot massage parlours, small saunas/bath rooms, barbershops, karaoke clubs, dancing halls and those who were self-employed (soliciting from the internet, a mobile phone or through a pimp). However, those at lower risk included those who worked at VIP clubs or big night clubs. Sexual partners were categorised as 'emotional partners', including non-paying sexual acts with boyfriends, fiancés and husbands in contrast with paying clients (regular or casual clients). To explore the strength of associations between unsafe sex and sex worker characteristics, three dependent variables were a priori selected, namely presence of any STI (participant had at least one infection of Neisseria gonorrhoeae (NG), Chlamydia trachomatis (CT), syphilis, Condyloma acuminatum, genital herpes simplex virus 2 (HSV-2) based on clinical diagnosis or laboratory screening depending on the STI); inconsistent or no condom use in the past month with any sexual partner (self-reported condom use in all sex acts (clients and emotional partners) over the past month); and no condom used during their last sex act with clients.

\section{Laboratory investigations}

Blood was collected and tested for HIV-1 antibodies (ELISA, Beijing BGI-GBI Biotech Co, China) and syphilis (rapid plasma reagin (RPR) test, Xinjiang Xindi Co, China). Positive HIV-1 ELISAs were confirmed by Western blot (Diagnostics HIV Blot 2.2, Genelabs, Redwood City, California, USA) and positive RPR tests for syphilis were confirmed by the Treponema pallidum particle assay test (Serodia TP-PA Fujirebio, Fuji, Japan). Endocervical swabs were collected and tested for NG and CT by PCR (AMPLICOR, Roche, Indianapolis, Indiana, USA). Investigations for HIV, syphilis, NG and CT were performed in the Reference Laboratory of the Kunming CDC. C acuminatum and genital HSV-2 infections were clinically diagnosed based on the Chinese STDs Diagnosis Protocol. ${ }^{30}$

\section{Statistical analysis}

Statistical tests were performed using Stata V.10.0. Variables from the data were initially presented using descriptive techniques. $\chi^{2}$ tests, Wilcoxon rank sum test, fisher's exact test and t test were used to detect associations among categorical variables, nonsymmetrically and symmetrically distributed continuous variables, respectively. Logistic regression was used to investigate the extent of the association between the dependent variables and exploratory variables, including socio-demographic, sex work characteristics, behavioural characteristics and status of health service use. Multivariable logistic regression models were adjusted 
for the exploratory variables found to be significantly associated $(p<0.1)$ in the binary logistic regression analysis, and those hypothesised a priori to be associated using a stepwise forwardfitting approach beginning with the covariate with the lowest $p$ value. Variables that did not markedly alter the model fit were removed from the model.

\section{RESULTS}

\section{Socio-demographic and economic characteristics}

Between July 2010 and February 2011, a total of 231 eligible and consenting women were recruited, with 201 (87\%) completing their interview and accepting STI and HIV testing.
Women had a mean age of 18.2 years $(\mathrm{SD}=1.0)$ and were predominantly of Han ethnicity (75.1\%; table 1). Approximately one-third of women were illiterate or only completed primary level schooling. The majority of respondents were single or never married $(71.6 \%)$ and $10 \%$ reported currently living with their parents. Sex work was the main source of income for most women (91\%). More than half of women (57\%) reported their recent monthly income to be between US\$150 and 500 . No significant differences in age, education level, marital status, residential status, ethnicity and living arrangements were identified between women who worked in higher-risk or lower-risk workplaces (table 1). Respondents working at higher-risk

Table 1 Socio-demographic characteristics of adolescent female sex workers aged 15-19 years enrolled in a cross-sectional survey in Yunnan, China $(n=201)$

\begin{tabular}{|c|c|c|c|c|}
\hline \multirow[b]{2}{*}{ Variable } & \multirow[b]{2}{*}{ All women $n / N(\%) \dagger$} & \multicolumn{3}{|c|}{ Characteristics by FSW workplace, n/N (\%)† } \\
\hline & & Lower-risk workplaceł & Higher-risk workplace§ & p Value* \\
\hline Age, mean years (SD) & $18.2(1.0)$ & $18.1(1.0)$ & $18.3(1.0)$ & $0.86^{* *}$ \\
\hline Education level & & & & 0.29 \\
\hline Illiterate or primary school & $59 / 201(29.4)$ & $26 / 105(24.8)$ & $33 / 96(34.4)$ & \\
\hline Middle school & $78 / 201(38.8)$ & $42 / 105(40.0)$ & $36 / 96(37.5)$ & \\
\hline High school & $64 / 201(31.8)$ & $37 / 105(35.2)$ & $27 / 96(28.1)$ & \\
\hline Current marital status & & & & 0.94 \\
\hline Never married or single & 144/201 (71.6) & $75 / 105(71.4)$ & $69 / 96(71.9)$ & \\
\hline Married or cohabiting & $57 / 201(28.4)$ & $30 / 105(28.6)$ & $27 / 96(28.1)$ & \\
\hline Residential status & & & & 0.22 \\
\hline Yunnan & $166 / 201(82.6)$ & $90 / 105(85.7)$ & 76/96 (79.2) & \\
\hline Other province & $35 / 201(17.4)$ & $15 / 105(14.3)$ & 20/96 (20.8) & \\
\hline Ethnicity & & & & 0.71 \\
\hline Han & $151 / 201(75.1)$ & $80 / 105(76.2)$ & $71 / 96(74.0)$ & \\
\hline Other ethnic group & $50 / 201(24.9)$ & $25 / 105(23.8)$ & $25 / 96(26.0)$ & \\
\hline Currently living with & & & & 0.11 \\
\hline Parents & $10 / 201(5.0)$ & $3 / 105(2.9)$ & $7 / 96(7.3)$ & \\
\hline Emotional partners & 69/201 (34.3) & $38 / 105(36.2)$ & $31 / 96(32.3)$ & \\
\hline Friends & $67 / 201(33.3)$ & $34 / 105(32.4)$ & $33 / 96(34.4)$ & \\
\hline Alone & $51 / 201(25.4)$ & $30 / 105(28.5)$ & $21 / 96(21.8)$ & \\
\hline Coercion-based site with handlers & $4 / 201(2.0)$ & 0 & $4 / 96(4.2)$ & \\
\hline \multicolumn{5}{|l|}{ Source of incomett } \\
\hline Sex work is main source & $182 / 200(91.0)$ & $102 / 104(98.1)$ & $80 / 96(83.3)$ & $<0.001$ \\
\hline \multicolumn{5}{|l|}{ Other sources of income } \\
\hline Parental/familial support & 30/201 (14.9) & $12 / 105(11.4)$ & 18/96 (18.8) & 0.14 \\
\hline Emotional partner's support & $29 / 201(14.4)$ & $16 / 105(15.2)$ & $13 / 96(13.5)$ & 0.73 \\
\hline Other sources of income & $18 / 201(9.0)$ & $7 / 105(6.7)$ & $11 / 96(11.5)$ & 0.23 \\
\hline Monthly income in past 6 months (in US\$) & & & & 0.018 \\
\hline$<150$ & $18 / 201(9.0)$ & $4 / 105(3.8)$ & $14 / 96(14.6)$ & \\
\hline $150-500$ & 114/201 (57.0) & $66 / 105(62.9)$ & $48 / 96(50.0)$ & \\
\hline$>500$ & $69 / 201(34.0)$ & $35 / 105(33.3)$ & $34 / 96(35.4)$ & \\
\hline Amount received from last client, median US\$ (IQR) & $80(48-160)$ & $128(80-160)$ & $48(32-136)$ & $<0.001^{* * *}$ \\
\hline Age at first sexual intercourse, mean years (SD) & $16.3(1.2)$ & $16.1(1.1)$ & $16.4(1.3)$ & $0.91^{* *}$ \\
\hline Duration in sex work & & & & 0.001 \\
\hline$\leq 6$ months & $107 / 201(53.2)$ & $43 / 105(41.0)$ & $64 / 96(66.7)$ & \\
\hline $7-12$ months & $66 / 201(33.8)$ & $45 / 105(42.9)$ & $21 / 96(21.9)$ & \\
\hline$>1$ year & $28 / 201(13.9)$ & $17 / 105(16.1)$ & $11 / 96(11.4)$ & \\
\hline
\end{tabular}

${ }^{*} p$ Value comparing women working at higher-risk versus lower-risk places using $\chi^{2}$ test unless indicated.

tUnless otherwise indicated.

¥Workplaces at lower risk for adolescent FSWs. Division is based on previous research and interview of key informants within local context and includes VIP clubs, night clubs.

$\S W$ orkplaces at higher risk for adolescent FSWs. Division is based on previous research and interview of key informants within local context and includes street walking, small roadside guesthouses with manager or pimp, foot massage parlours, saunas/bath rooms, barbershops, inns/hotels, karaoke clubs, dancing halls.

IThe minimum legal age for marriage is generally 20 for women 22 for men; in many rural areas, there is no restrictive social-cultural taboo for young people under the legal age of marriage to get engaged and cohabit without registration, so called 'de facto marriage'; in this case, some participants (1\%) self-reported to be married.

** Student's t test.

***Wilcoxon rank sum test.

††Multiple-response question.

FSW, female sex worker. 
venues were less likely to be full-time sex workers $(83.3 \%$ vs $98.1 \%, p<0.001)$; they were more likely to have lower monthly income (<US\$150; $14.6 \%$ vs $3.8 \%, p=0.018$ ); and earned less from their last clients (median US\$48 vs US\$128, $\mathrm{p}<0.001$ ).

\section{Substance use}

In the past 6 months, most women reported using tobacco $(67.7 \%)$ and/or alcohol $(74.1 \%)$, and $67.5 \%$ reported using substances everyday or almost everyday. Eight percent of respondents reported using illicit drugs. Respondents who were working at higher-risk venues were less likely to use tobacco $(56.2 \%$ vs $78.1 \%, p=0.001)$ or alcohol (59.4\% vs $87.6 \%$; $\mathrm{p}<0.001)$ than those at lower-risk venues (table 2).

\section{Sexual behaviour}

A total of $75.3 \%$ of women reported using a condom with their last male client. Consistent condom use during the last month with clients was reported by $55 \%$, whereas only $22.2 \%$ reported practising consistent condom use with their emotional partners. About half (50.3\%) of respondents reported having sex while feeling drunk at least once in the past week, of whom $56.4 \%$ reported this act was unprotected. Respondents who were working at higher-risk venues were more likely to report having a shorter duration of sex work, for example, less than 6 months $(66.7 \%$ vs $41 \%, p=0.003)$, and having more clients in the past week $(p=0.001)$ compared with women working at lower-risk venues.

\section{HIV and sexually transmitted infections}

Nearly three-quarters of young women (74.0\%) reported having STI symptoms in the past year, including vaginal itching or irritation, burning urination, lower abdominal pain, unusual leucorrhoea, or rashes, lumps or blisters around the genitals or anus (table 2). One-third (30.4\%) of women had one or more

Table 2 Sexual behaviour, drug use and HIV/STIs among adolescent female sex workers

\begin{tabular}{|c|c|c|c|c|}
\hline \multirow[b]{2}{*}{ Variable } & \multirow[b]{2}{*}{ All women, n/N (\%)† } & \multicolumn{3}{|c|}{ Characteristics by FSW workplace, n/N (\%)† } \\
\hline & & Lower-risk workplace & Higher-risk workplace & p Value* \\
\hline \multicolumn{5}{|l|}{ Sexual behaviour } \\
\hline Number of emotional partners (past 3 months) & & & & 0.24 \\
\hline Only 1 & $24 / 192(12.5)$ & $17 / 102(16.7)$ & $7 / 90(7.8)$ & \\
\hline $2-4$ & $75 / 192(39.1)$ & $35 / 102(34.3)$ & $40 / 90(44.5)$ & \\
\hline $5-10$ & $67 / 192(34.9)$ & $35 / 102(34.3)$ & $32 / 90(35.5)$ & \\
\hline$>10$ & $26 / 192(13.5)$ & $15 / 102(14.7)$ & $11 / 90(12.2)$ & \\
\hline Number of clients (past week), median (IOR) & $2(1-3)$ & $1(1-2)$ & $2(1-4.5)$ & $0.001^{* *}$ \\
\hline Condom used during last paid sex act & $146 / 194(75.3)$ & $76 / 105(72.4)$ & $70 / 89(78.7)$ & 0.31 \\
\hline \multicolumn{5}{|l|}{ Consistent condom use (last month) } \\
\hline With paying client & $105 / 191(55.0)$ & $57 / 99(57.6)$ & $48 / 92(52.2)$ & 0.13 \\
\hline With emotional partner & $42 / 189(22.2)$ & $27 / 103(26.2)$ & $15 / 83(18.1)$ & 0.41 \\
\hline At least one sex act while feeling drunk (past week) & $78 / 155(50.3)$ & $48 / 90(53.3)$ & $30 / 65(46.2)$ & 0.38 \\
\hline At least one sex act without a condom while feeling drunk (past week) & $48 / 78(56.4)$ & $27 / 48(56.3)$ & $17 / 30(56.7)$ & 0.16 \\
\hline \multicolumn{5}{|l|}{ Substance using behaviour } \\
\hline \multicolumn{5}{|l|}{ Any substance used (past 6 months) $\ddagger$} \\
\hline Illicit drugs§ & $16 / 201(8.0)$ & $8 / 105(7.6)$ & $8 / 96(8.3)$ & 0.85 \\
\hline Tobacco & $136 / 201(67.7)$ & $82 / 105(78.1)$ & $54 / 96(56.2)$ & 0.001 \\
\hline Alcohol & $149 / 201(74.1)$ & $92 / 105(87.6)$ & $57 / 96(59.4)$ & $<0.001$ \\
\hline Frequency of substance use (past 6 months) & & & & 0.03 \\
\hline Everyday or almost everyday & $112 / 166(67.5)$ & $69 / 95(72.6)$ & $43 / 71(60.6)$ & \\
\hline 1 or 2 days weekly & $7 / 166(4.2)$ & $1 / 95(1.1)$ & $6 / 71(8.0)$ & \\
\hline Occasionally & $47 / 166(28.3)$ & $25 / 95(26.3)$ & $22 / 71(31.0)$ & \\
\hline Emotional partners involved in substance use & & & & 0.44 \\
\hline Never used & $52 / 139(37.4)$ & $35 / 85(41.2)$ & $19 / 54(31.5)$ & \\
\hline Previously used & $31 / 139(22.3)$ & $19 / 85(22.4)$ & $12 / 54(22.2)$ & \\
\hline Currently using & $56 / 139(40.3)$ & $31 / 85(36.4)$ & $25 / 54(46.3)$ & \\
\hline \multicolumn{5}{|l|}{ HIV and STIs } \\
\hline HIV positive & $2 / 201(1.0)$ & 0 & $2 / 96(2.1)$ & $0.22 * * *$ \\
\hline Self-reported symptoms of STI (past year) & $148 / 200(74.0)$ & 73/104 (70.2) & 75/96 (78.1) & 0.20 \\
\hline Any STI (based on clinical or laboratory screening) & $61 / 201(30.4)$ & $24 / 105(22.9)$ & $37 / 96(38.5)$ & 0.016 \\
\hline \multicolumn{5}{|l|}{ STI prevalence based on clinical diagnosis or laboratory screening } \\
\hline Neisseria gonorrhoeae & $25 / 191(13.1)$ & $4 / 100(4.0)$ & $21 / 91(23.1)$ & $<0.001^{* * *}$ \\
\hline Chlamydia trachomatis & $28 / 191(14.7)$ & $17 / 100(17.0)$ & $11 / 91(12.1)$ & 0.33 \\
\hline Syphilis & $3 / 201(1.5)$ & $1 / 105(0.9)$ & $2 / 96(2.1)$ & $0.47^{* * *}$ \\
\hline Condyloma acuminatum & $13 / 189(6.9)$ & $4 / 100(4.0)$ & $9 / 89(10.1)$ & $0.09 * * *$ \\
\hline Genital HSV-2 & $1 / 189(0.5)$ & $1 / 100(1.0)$ & 0 & $0.52^{* * *}$ \\
\hline
\end{tabular}


STI during study screening based on clinical or laboratory evaluation. STI prevalence was particularly high among women working at higher-risk venues $(38.5 \%)$ compared with lower-risk venues $(22.9 \%$; $p=0.016)$. The prevalence of syphilis, NG, CT, C acuminatum and genital HSV-2 infection detected during laboratory screening was 1.5\%, 13.1\%, 14.7\%, 6.9\% and $0.5 \%$, respectively. Participants who were working at higher-risk venues were significantly more likely to have NG $(23.1 \%$ vs $4.0 \%, \mathrm{p}<0.001)$, and more likely to have $C$ acuminatum infection $(10.1 \%$ vs $4.0 \%, p=0.09$; table 2$)$. Of 201 participants, two women $(1 \%)$ tested HIV positive and both were working at higher-risk venues.

\section{Health-seeking behaviour and service use}

The majority of women reported a need for additional health knowledge (77.1\%), free condom distribution (50.8\%) and low-cost STI diagnosis and treatment services (53.7\%; table 3 ). Of women who reported STI symptoms in the past year $(n=148)$, about half reported having taken self-treatment for STI symptoms $(52.4 \%)$, and only $25.5 \%$ reported seeking care at public health facilities, similarly between those working at higher-risk and lower-risk venues. Compared with the lowerrisk group, those working at higher-risk workplaces were significantly less likely to have received peer education and outreach services $(62.5 \%$ vs $87.5 \%, p<0.001)$, and free condoms $(59.3 \%$ vs $93.3 \%, \mathrm{p}<0.001)$; and were more likely to have received HIV testing $(43.8 \%$ vs $17.1 \%, \mathrm{p}<0.001)$. At the same time, they were less likely aware of test results $(35.7 \%$ vs $72.2 \%, \mathrm{p}=0.009)$.

\section{Factors associated with unprotected sex and STls}

Among adolescent FSWs, the main predictor independently associated with having any STI was access to free condoms in the past year (table 4). Adolescent FSWs who did not receive services of condom provision were 2.5 times more likely to have at least one STI (95\% CI 1.1 to $5.7 ; p=0.028)$ than those with service exposure. There seemed to be a trend for women working at higher-risk venues to be at increased risk for having any STI (38.5\% and $22.9 \%$, respectively), although this was no longer statistically significant after adjustment of other factors.

Adolescent FSWs who reported illicit drug use (adjusted OR $8.54,95 \%$ CI 1.04 to $70.41 ; p=0.048$ ) and received primary education or less (adjusted OR 3.07, 95\% CI 1.09 to $8.62 ; p=0.033$ ) were more likely to report unprotected sex in the past month with any partner compared with women with higher education. In addition, shorter duration in sex work was independently associated with unprotected sex, with less risky behaviour over time.

Four factors were significantly associated with no condom used during last paid sex act, including earlier age at sex debut, currently married or cohabiting, living with current partner for less than 6 months, and not having received HIV testing in the last year.

\section{DISCUSSION}

To our knowledge, these results are the first to document sexual risk behaviour, clinical and laboratory based HIV/STI screening rates, and health-seeking behaviour of this vulnerable and marginalised group of adolescent FSWs in China. Compared with previous FSW studies (mainly focusing on adult FSWs) in China, ${ }^{10}{ }^{23-26}$ our study did not show many significant differences in demographic, social and sexual behavioural characteristics between women working at the higher-risk and lower-risk venues based on the traditionally divided risk groups in China. Although respondents working at higher-risk workplaces were earning less despite having more clients in the past week, both groups were found to report high numbers of sexual partners and low condom use. Half the young women reported five or more emotional partners in the past 3 months, with whom the rate of consistent condom use

Table 3 Health-seeking behaviour and access to health services among Chinese female sex workers

\begin{tabular}{|c|c|c|c|c|}
\hline \multirow[b]{2}{*}{ Variable } & \multirow[b]{2}{*}{ All women, $n / N(\%) \dagger$} & \multicolumn{3}{|c|}{ Characteristics by FSW workplace, n/N (\%)† } \\
\hline & & Lower-risk workplace & Higher-risk workplace & p Value* \\
\hline \multicolumn{5}{|l|}{ Need for health services } \\
\hline Free condom distribution & 102/201 (50.8) & $55 / 105(52.3)$ & $47 / 96$ (47.8) & 0.63 \\
\hline Service to increase health knowledge & $155 / 201(77.1)$ & 75/105 (71.4) & $80 / 96(83.3)$ & 0.045 \\
\hline Low-cost STI diagnosis and treatment & $108 / 201(53.7)$ & $51 / 105(48.6)$ & $57 / 96(59.4)$ & 0.13 \\
\hline Low-cost reproductive health service & $83 / 201(41.3)$ & $46 / 105$ (43.8) & $37 / 96(38.5)$ & 0.45 \\
\hline Free clean needle and syringe distribution & 23/201 (11.4) & 19/105 (18.1) & $4 / 96(4.1)$ & $0.002^{* *}$ \\
\hline Detoxification treatment & $7 / 201(3.5)$ & $4 / 105$ (3.8) & $3 / 96(3.1)$ & $0.55^{* *}$ \\
\hline \multicolumn{5}{|l|}{ Health-seeking behaviour } \\
\hline \multicolumn{5}{|l|}{ Sought care for STI symptoms (past year)‡ } \\
\hline At private clinic or hospital & $55 / 146(37.7)$ & $22 / 70(31.4)$ & $33 / 76(43.4)$ & 0.14 \\
\hline At public clinic or hospital & $37 / 145(25.5)$ & $16 / 70(22.9)$ & $21 / 75(28.0)$ & 0.48 \\
\hline Self-treatment for STI & $76 / 145(52.4)$ & $41 / 70(58.8)$ & $35 / 75(46.7)$ & 0.15 \\
\hline \multicolumn{5}{|l|}{ Health services use } \\
\hline Received peer education/outreach (past year) $\ddagger$ & $151 / 200(75.5)$ & $91 / 104(87.5)$ & $60 / 96(62.5)$ & $<0.001$ \\
\hline Received free condoms (past year) $\ddagger$ & 155/201 (77.1) & $98 / 105$ (93.3) & $57 / 96(59.4)$ & $<0.001$ \\
\hline Received methadone/clean needles $\ddagger$ & $13 / 199(6.5)$ & $9 / 105(8.6)$ & $4 / 94(4.3)$ & $0.17^{* *}$ \\
\hline Received HIV testing(past year) & $60 / 201(29.9)$ & $18 / 105(17.1)$ & $42 / 96(43.8)$ & $<0.001$ \\
\hline Aware of HIV testing results & $28 / 60(46.7)$ & $13 / 18(72.2)$ & $15 / 42(35.7)$ & 0.009 \\
\hline
\end{tabular}


Table 4 Predictors of sexual risk behaviour defined as presence of any sexually transmitted infection at screening, inconsistent condom use in the past month and no condom used during last sex act among 201 adolescent female sex workers

\begin{tabular}{|c|c|c|c|c|c|c|}
\hline Variable & Risk factor & $\%(\mathbf{n} / \mathbf{N})$ & Crude OR (95\% CI) & p Value & Adjusted OR (95\% Cl) & p Value \\
\hline \multirow{12}{*}{ Any STI } & 19 years & $28.0(27 / 97)$ & 1.0 & 0.56 & & \\
\hline & $15-18$ years & $33.0(34 / 104)$ & $1.26(0.69$ to 2.31$)$ & & & \\
\hline & Lower risk & $22.9(24 / 105)$ & 1.0 & 0.016 & & \\
\hline & Higher risk & $38.5(37 / 96)$ & $2.12(1.13$ to 3.95$)$ & & & \\
\hline & Sex work as main source of income & & & & & \\
\hline & Amount received from last client & & & & & \\
\hline & US $\$ 4-75$ & $37.0(34 / 92)$ & 1.0 & 0.051 & & \\
\hline & US\$76-150 & $20.8(10 / 48)$ & $0.45(0.20$ to 1.03$)$ & & & \\
\hline & $>$ US $\$ 150$ & $19.4(6 / 31)$ & 0.41 (0.15 to 1.12$)$ & 0.07 & & \\
\hline & Received free condoms (past year) & & & & & \\
\hline & Yes & $25.2(39 / 155)$ & 1.0 & 0.003 & 1.0 & 0.028 \\
\hline & No & $47.8(22 / 46)$ & $2.72(1.35$ to 5.47$)$ & & $2.51(1.11$ to 5.70$)$ & \\
\hline \multirow{13}{*}{$\begin{array}{l}\text { Inconsistent or no condom use in } \\
\text { past month with any sexual partners }\end{array}$} & Middle school & $73.0(57 / 78)$ & $1.00(0.47$ to 2.13$)$ & 0.99 & 0.90 (0.41 to 1.99$)$ & 0.79 \\
\hline & Illiterate or primary school & $86.4(51 / 59)$ & $2.69(1.00$ to 7.23$)$ & 0.04 & $3.07(1.09$ to 8.62$)$ & 0.033 \\
\hline & Choose sex work for earning money & & & & & \\
\hline & No & $82.0(73 / 89)$ & 1.0 & 0.05 & & \\
\hline & Yes & $72.3(81 / 112)$ & $0.50(0.25$ to 1.07$)$ & & & \\
\hline & Duration in sex work & & & & & \\
\hline & $>1$ year & $64.3(18 / 28)$ & 1.0 & & 1.0 & \\
\hline & $7-12$ months & $80.3(53 / 66)$ & 2.27 (0.83 to 6.17$)$ & 0.10 & $2.91(0.098$ to 8.60$)$ & 0.044 \\
\hline & $<6$ months & $79.0(83 / 107)$ & $2.10(0.84$ to 5.25$)$ & 0.10 & $2.90(1.02$ to 8.19$)$ & 0.054 \\
\hline & Illicit drug use (past 6 months) & & & & & \\
\hline & No & $75.7(140 / 185)$ & 1.0 & & 1.0 & \\
\hline & Yes & $87.5(14 / 16)$ & 4.40 (0.55 to 35.02$)$ & 0.12 & $8.54(1.04$ to 70.41$)$ & 0.048 \\
\hline & Received HIV testing (past year) & & & & & \\
\hline \multirow{8}{*}{ No condom used during last sex act with client } & Never married, separated or single & $27.8(40 / 144)$ & 1.0 & & 1.0 & \\
\hline & Married or cohabiting & $14.0(8 / 57)$ & $0.42(0.18$ to 0.98$)$ & 0.038 & $0.37(0.15$ to 0.92$)$ & 0.033 \\
\hline & Duration of living with current partner & & & & & \\
\hline & $\leq 6$ months & $31.5(28 / 89)$ & 1.0 & & 1.0 & \\
\hline & $>6$ months & $18.0(20 / 111)$ & 0.50 (0.26 to 0.99$)$ & 0.041 & 0.40 (0.19 to 0.82$)$ & 0.014 \\
\hline & Received HIV testing (past year) & & & & & \\
\hline & Yes & $10.0(6 / 60)$ & 1.0 & & 1.0 & \\
\hline & No & $29.8(42 / 141)$ & 3.87 (1.50 to 9.96$)$ & 0.002 & $2.88(1.11$ to 7.50$)$ & 0.030 \\
\hline
\end{tabular}

Any STI, reported at least one STI based on clinical diagnosis or laboratory screening from Neisseria gonorrhoeae/Chlamydia trachomatis/syphilis/Condyloma acuminatum/genital herpes simplex virus 2 infections.

STI, sexually transmitted infection.

was very low (22.2\%). Even among sex acts with clients, consistent condom use over the last month was relatively low $(55.0 \%)$ compared with reports from other studies. ${ }^{12} \begin{array}{lll}23 & 31 & 32\end{array}$ The homogeneity of adolescent FSWs regarding risk-taking behaviour suggests that intervention activities need to focus on adolescent FSWs working at any workplace. Furthermore, governments and policymakers need to consider the influence of legal crackdowns of FSWs, which leads to marginalisation and migration and impedes health workers from providing continuous intervention services.

This study noted that adolescent FSWs who recently started sex work more often reported unprotected sex, which concurs with our finding that they received less frequent free condom service $(68.2 \%$ vs $89.3 \%, p=0.006)$ and less frequent outreach or peer education services $(67.3 \%$ vs $82.1 \%, p=0.014)$ compared with women who had worked longer in the sex trade (more than 1 year). Additionally, level of education was significantly associated with inconsistent condom use, highlighting the need for integration of sex education into existing primary and secondary schooling. For illiterate adolescent FSWs, existing 'youth centres' or 'drop-in centres' could be reoriented or reprioritised to serve this specific population with appropriate information.

Previous studies, largely among adult FSWs, show similar HIV and syphilis prevalence rates to our study. ${ }^{26} 28$ 33-35 Nearly a third of participants had at least one STI, and particularly adolescents working at higher-risk venues were at increased 
risk, potentially due to the lower reported access to STI prevention and treatment services. Moreover, women who reported having accessed HCT services were less likely to report unprotected sex. This highlights the need for universal access to youth-friendly counselling, testing and treatment services. Overall, this information justifies intensified targeted programmes to increase HIV and STI prevention, treatment and care activities, particularly at higher-risk venues and among newcomers.

Eight percent of respondents reported using illicit drugs and related increasing sexual risk behaviour, consistent with other studies of FSWs. ${ }^{23}$ Various studies have shown associations between alcohol use and sexual risk behaviour, and HIV and STIs among sex workers. ${ }^{19} 36$ This poses a significant risk, with nearly three-quarters of these adolescents using alcohol.

There are several potential limitations to this study. During the survey period, illegal drug use and sex work were facing police crackdown nationwide, which made random sampling strategies impossible. Additionally, resulting difficulties in disclosure of illegal drug use may have resulted in an underestimation of the prevalence of drug use.

In summary, current health services, social development and livelihood interventions, and youth programmes are failing to substantially reach these most vulnerable girls in society. Innovative and sustainable approaches to extend existing services are needed to improve the health and wellbeing of these young women. Existing sex worker drop-in centres need reorientation to improve services relevant and accessible to young people. Future studies should assess the effectiveness and impact of such interventions and could include recruitment and training of adolescent sex worker peer educators to generate new innovative and targeted strategies, and to improve confidential, non-judgmental counselling and testing for HIV and affordable STI treatment.

\section{Key messages}

- Adolescent female sex workers (FSWs) in China aged1519 years report frequent unprotected sex and were diagnosed with high rates of sexually transmitted infections (STIs), confirming their vulnerability.

- Unprotected sex was more often reported by adolescent FSWs who only recently entered into sex work, requiring particular attention.

- Adolescent FSWs who accessed STI prevention services, including peer education based health promotion and condom access, reported improved sexual behaviour.

- Scaling up of sexual and reproductive health interventions targeting adolescent FSWs at all work venues, including those perceived as low risk, is needed.

Acknowledgements The authors appreciate the coordinated efforts and dedication of the local support groups and the AIDS department at the Kunming Public Health Bureau. The authors thank all participants for their time and trust.

Contributors XZ designed and implemented the study, conducted data collection and analysis, and wrote the first draft of the manuscript. SL participated in the design of the study, and supervised the analysis and manuscript writing. MT and YL participated in the design of the study and critically appraised the project protocol; WL coordinated the laboratory testing of HIV/STIs and assisted in the interpretation of the findings. All authors critically reviewed the manuscript, contributed to its revision and approved the final version.

Funding This study received partial support from the Accelerating AIDS Action in China Project funded by Bill \& Melinda Foundation (funding number (2010YNworkplan-8)); and the HIV Research Trust Scholarships (funding number (HIVRT11-06)) award to X D Zhang. The authors gratefully acknowledge the contribution to this work of the Victorian Operational Infrastructure Support Program. We would also like to thank the peer reviewers of Sexually Transmitted Infections for their valuable feedback.

\section{Competing interests None.}

Ethics approval The ethical committee of the Kunming Public Health Bureau.

Provenance and peer review statement Not commissioned; externally peer reviewed.

Open Access: This is an Open Access article distributed in accordance with the Creative Commons Attribution Non Commercial (CC BY-NC 3.0) license, which permits others to distribute, remix, adapt, build upon this work non-commercially, and license their derivative works on different terms, provided the original work is properly cited and the use is non-commercial. See: http://creativecommons.org/ licenses/by-nc/3.0/

\section{REFERENCES}

1. UNAIDS. Securing the Future Today: Synthesis of Strategic Information on HIV and Young People. Geneva: UNAIDS, 2011

2. Zheng $\mathbf{X}-\mathbf{Y}$, Chen $\mathrm{G}$, Han $\mathbf{Y}-\mathbf{L}$, et al. Survey of youth access to reproductive health in China. Popul Dev 2010;16:2-16.

3. Staras SAS, Tobler AL, Maldonado-Molina MM, et al. Riskier sexual partners contribute to the increased rate of sexually transmitted diseases among youth with substance use disorders. Sex Transm Dis 2011;38:413-18.

4. UNICEF. Opportunity in Crisis: Preventing HIV from early Adolescence to Young Adulthood. New York: Nations Children's Fund, 2011.

5. Yunnan Statistics Bureau. Yunnan 2010 Report of Sixth Population Census. Kunming: Yunnan Statistics Bureau, 2011

6. Duan S, Shen S, Bulterys $M$, et al. Estimation of HIV-1 incidence among five focal populations in Dehong, Yunnan: a hard hit area along a major drug trafficking route. BMC Public Health 2010;10:180.

7. Peng Z-H, Cheng Y-J, Reilly KH. Spatial distribution of HIV/AIDS in Yunnan province, People's Republic of China. Geospatial Health 2011;5:177-82.

8. Tucker J, Ren X, Sapio F, et al. Incarcerated sex workers and HIV prevention in China: social suffering and social justice countermeasures. Soc Sci Med 2010; $70: 121-9$

9. Li L, Chen L, Yang Y. Population estimation, HIV/AIDS knowledge awareness and risk behaviour among female sex workers in Kunming, Yunnan. J Dermatol Venereol 2009;31:1-2.

10. Jun J, Worth H, Ying HY. HIV in China: Understanding the Social Aspects of the Epidemic. Sydney, NSW: University of New South Wales Press, 2010.

11. UNAIDS. Protecting Sex Workers Key to Preventing Spread of HIV. Geneva: UNAIDS, 2011

12. Fang X-Y, Li X-M, Yang H-M. Profile of female sex workers in a Chinese county: does it differ by where they came from and where they work? World Health Popul 2007:9:46-64.

13. TNI. A Report of Expert Seminar on Amphetamine Type Stimulants and Harm Reduction: Experiences from China. Myanmar and Thailand: Transnational Institute, 2010:20.

14. Blickman T. The ATS Boom in Southeast Asia. Myanmar and Thailand: Transnational Institute, 2009:18.

15. Li Y, Detels R, Lin P, et al. Prevalence of HIV and STls and associated risk factors among female sex workers in Guangdong province, China. JAIDS J 2010;53: S48-53.

16. Poon AN, Li Z, Wang N, et al. Review of HIV and other sexually transmitted infections among female sex workers in China. AIDS Care 2011;23(Suppl 1):5-25

17. Heckathorn DD, Semaan S, Broadhead RS. Extensions of respondent-driven sampling: a new approach to the study of injection drug users aged 18-25. AIDS Behavior 2002;6:55-67.

18. National Center for Diseases Control and Prevention. National HIVIAIDS Sentinel Surveillance Protocol (2009 Version). Beijing: National Center for Diseases Control and Prevention, 2009:147.

19. Chersich MF, Luchters SM, Malonza IM, et al. Heavy episodic drinking among Kenyan female sex workers is associated with unsafe sex, sexual violence and sexually transmitted infections. Int J STD AIDS 2007:18:764-9.

20. Luchters S, Chersich MF, Rinyiru A, et al. Impact of five years of peer-mediated interventions on sexual behavior and sexually transmitted infections among female sex workers in Mombasa, Kenya. BMC Public Health 2008;8:143.

21. State Council of the People's Republic of China. Regulation on the Prevention and Treatment of HIVIAIDS. Beijing: State Council of the People's Republic of China, 2007.

22. Ministry of Health of the People's Republic of China. Management Regulations on Free and Voluntary HIV Testing. Beijing: Ministry of Health, 2004.

23. Wang H, Chen RY, Ding G, et al. Prevalence and predictors of HIV infection among female sex workers in Kaiyuan City, Yunnan Province, China. Int $\mathrm{J}$ Infect Dis 2009:13:162-9 
24. Ruan Y, Cao X, Oian H-Z, et al. Syphilis among female sex workers in Southwestern China: potential for HIV transmission. Sex Transm Dis 2006;33:719-23.

25. Tucker JD. The social context of sexual HIV prevention among female sex workers in China. Int J Epidemiol. Published Online First: 15 February 2011. doi: 10.1093/ije/ dyr021

26. Ou-Yang N, Xu F. A study on 2009 HIV surveillance data among female sex workers in Dong Chuan, Kunming. J Soft Sci Health 2010;24:471-3.

27. Li Y, Detels R, Lin P, et al. Difference in risk behaviors and STD prevalence between street-based and establishment-based FSWs in Guangdong Province, China. AIDS Behav 2012;16:943-51.

28. Chen XS, Wang Q0, Yin YP, et al. Prevalence of syphilis infection in different tiers of female sex workers in China: implications for surveillance and interventions. $B M C$ Infect Dis 2012;12:7.

29. Ministry of Health of the People's Republic of China. Guidelines for Intervention Towards High Risk Behavior Leading to HIVIAIDS. Beijing: Ministry of Health of the People's Republic of China, 2005

30. National Center for STD Control. Guidelines for Diagnosis and Treatment of Sexually Transmitted Diseases. Beijing: National Center for Diseases Prevention and Control, 2006:108.
31. Couture MC, Sansothy N, Sapphon V, et al. Young women engaged in sex work in Phnom Penh, Cambodia, have high incidence of HIV and sexually transmitted infections, and amphetamine-type stimulant use: new challenges to HIV prevention and risk. Sex Transm Dis 2011;38:33-9.

32. Nguyen TV, Van Khuu N, Thi Le $\Pi$, et al. Sexually transmitted infections and risk factors for gonorrhea and chlamydia in female sex workers in Soc Trang, Vietnam. Sex Transm Dis 2008;35:935-40.

33. Zhang J, Xiang L, Jia-Yu J. 2010 sentinel surveillance data analysis on FSWs in Wu Hua, Kunming. J China Health 2010;29:318.

34. Zhu BY, Bu J, Huang PY, et al. Epidemiology of sexually transmitted infections, HIV, and related high-risk behaviors among female sex workers in Guangxi autonomous region, China. J Infect Dis 2012;65:75-8.

35. Li J, Chen XS, Merli MG, et al. Systematic differences in risk behaviors and syphilis prevalence across types of female sex workers: a preliminary study in Liuzhou, China. Sex Transm Dis 2012;39:195-200.

36. Luchters S, Geibel S, Syengo M, et al. Use of AUDIT, and measures of drinking frequency and patterns to detect associations between alcohol and sexual behaviour in male sex workers in Kenya. BMC Public Health2011; 11:384. 